\title{
PROPAGATION OF SURFACE WAVES IN ASPHALT PAVEMENTS GENERATED BY DIFFERENT LOAD IMPULSE OF FALLING WEIGHT DEFLECTOMETER
}

\author{
Jozef KOMAČKA ${ }^{1, *}$, Ilja BŘEZINA ${ }^{2}$ \\ ${ }^{1}$ Department of Highway Engineering, Faculty of Civil Engineering, University of Žilina, Univerzitná \\ 8215/1, 01026 Žilina, Slovakia. \\ ${ }^{2}$ Transport Research Centre, Líšeňská 33a, 63600 Brno, Czech Republic. \\ corresponding author: jozef.komacka@fstav.uniza.sk.
}

\begin{abstract}
The propagation of waves generated by load impulse of two FWD types was assessed using test outputs in the form of time history data. The calculated travel time of wave between the receiver in the centre of load and others receivers showed the contradiction with the theory as for the receivers up to $600(900) \mathrm{mm}$ from the centre of load. Therefore, data collected by the sensors positioned at the distance of 1200 and $1500 \mathrm{~mm}$ were used.

The influence of load magnitude on the waves propagation was investigated via the different load force with approximately the same load time and vice versa. Expectations relating to the travel time of waves, depending on the differences of load impulse, were not met. The shorter travel time of waves was detected in the case of the lower frequencies. The use of load impulse magnitude as a possible explanation was not successful because opposite tendencies in travel time were noticed.
\end{abstract}

\author{
Keywords: \\ Load; \\ Surface; \\ Wave; \\ Deflectometer; \\ Pavement.
}

\section{Introduction}

Bearing capacity of asphalt pavements is a variable technical parameter related to pavement performance. The pavement condition from bearing capacity point of view is tested by various diagnostic devices. Falling Weight Deflectometers (FWD) represent one group of ones. The test procedure consists of the generation of a load impulse and recording pavement response to load by sensors that are positioned at different distances from the load centre. The load impulse is registered as the change of load force and pavement response is obviously represented as the change of pavement surface deflection (i.e. the vertical movement of a pavement surface) at the position of the sensor. The changes of load force and deflections are recorded in time scale and stored in the time history file. Obviously, only the maximum values of the deflections are used for subsequent evaluation.

Several manufacturers construct the FWDs and the variations in the FWD design can lead to the differences in load impulse. According to [1], most FWDs have a load rise time from start of the pulse to peak of between 5 and 30 milliseconds and have a load pulse base width of between 20 and 60 milliseconds. Moreover, each of FWDs has the possibility to change the magnitude of the load force using the variable drop heights of the falling mass. The differences in the load impulse time of various FWDs can be important because the load impulse time influences the value of pavement surface deflections although the load magnitude is the same. The comparative studies of various FWD have proved the difference in the deflections measured at the same points [2]. Then, when the usual methods of pavement (layers) stiffness determination based on the theory of elastic and isotropic half space or multi-layered system on half space are applied, the modulus calculated from the central deflection or deflection bowl will be also different.

The time history file, as one of the outputs of diagnostic by FWD, contains data over time. Using this, it is possible to identify the time shift in the change of deflection at the individual position of the FWD sensors. It means the waves generated by load impulse propagate from the load area to 
surroundings. This opens the possibility to assess the pavement stiffness (modulus) using the principle of the spectral analysis surface waves (SASW) method. In [3] is mentioned, the method has been introduced by Nazarian and Stokoe [4] as an extension of a steady-state Rayleigh wave technique by Richart et al. [5]. The SASW method is used to determine shear modulus profiles of a site from the velocity of Rayleigh waves. The SASW test procedure includes the generation of waves by load impulse (obviously harmonic with different frequencies) and monitoring of shear waves propagation using receivers placed at a known distance from the load source on the surface of the investigated site. Thereafter, the processing of data allows determining the propagation velocity of shear waves. Based on the assumed shear/Rayleigh wave ratio [5], the velocity of Rayleigh waves can be determined and the dispersion curve for the load frequency or wavelength constructed. Taking into account knowledge, the various frequencies of applied load generate different wavelengths that propagate with different depth ranges and the Rayleigh waves velocity depends on the frequency (or wavelength) and properties of material within the propagation depth range, it is possible to differentiate site profile stiffness using the various frequencies of load impulse.

The FWD test procedure in basically in accordance with the SASW test procedure used to obtain field data. The only important difference relates to load impulse generation. It is not harmonic and the frequency of a load impulse is for a FWD predetermined by his load pulse time and varies in very narrow range. It means the depth of surface waves propagation is relatively constant. As FWDs have the different load impulse time, the depth of surface waves propagation differs. It can leads to the different wave velocity if there is a variability of material properties along the depth. The distance of FWD receivers and their spacing from the load area is another question. In [6], there are recommendations regarding the array length, the receiver spacing and the source offset for SASW field data acquisition. The array length should be at least equal to the maximum desired wavelength, which more or less corresponds to twice the desired investigation depth. As for FWDs, the distance of the most distant receiver is obviously limited by the length of the support beam and depending on the FWD type it can vary approximately from $1500 \mathrm{~mm}$ to $2100 \mathrm{~mm}$. It should be sufficient to investigate the site to the depth of between $750 \mathrm{~mm}$ and $1050 \mathrm{~mm}$. It seems acceptable because it is more than the common thickness of pavement structures and a part of pavement subgrade could be also included. The common receiver spacing their number and the offset between the load plate and first receiver is for all FWD types much shorter than recommended in [6] for stiffness profile determination. It is questionable if it is suitable to reliably sample wavelengths associated with the propagation of the impulse. Therefore, the experiments on various pavement structures were performed with two different FWD from the load impulse time point of view (KUAB and Dynatest). The priority aim was to investigate the possibility to identify the surface waves propagation using FWD time history data. Moreover, the influence of various factors that could influence the wave propagation was assessed.

\section{Experimental tests and results}

The first stage of tests was executed on the six asphalt pavements using FWD KUAB $2 m-50$. The total thickness of the pavements and also the thickness of individual pavement layers was the same. Only the quality of materials was combined in some layers. Moreover, the subgrade stiffness was not the same in all pavements. These tests were focused on the influence of load magnitude and pavement structure composition on surface waves propagation. Two levels of the load magnitude (approx. $25.5 \mathrm{kN}$ and $50 \mathrm{kN}$ ) were generated using the different drop heights of the falling mass. Complementary, the FWD KUAB 2m-50 and FWD Dynatest 8002-236 were used to test one asphalt pavement that significantly differed from six previous ones. The reason was to investigate the influence of the load impulse time and pavement structure composition. The sampling interval for the pavements $1-6$ was $0.87 \mathrm{~ms}$. In the case of the pavement 7 , the sampling interval was $0.23 \mathrm{~ms}$ for FWD Kuab and $0.05 \mathrm{~ms}$ for FWD Dynatest. It means the sampling frequency was higher than the maximum frequency of the propagating load impulse.

The time history files from the tests were used to verify the differences in load magnitude and load impulse time. The change of the load force values in time scale confirms the difference of the FWD KUAB and FWD Dynatest load impulse time (Fig. 1 on the left). Moreover, a slight difference of the load impulse time can be observed in Fig. 1 on the right, showing the change of FWD KUAB load force for both drop heights. 

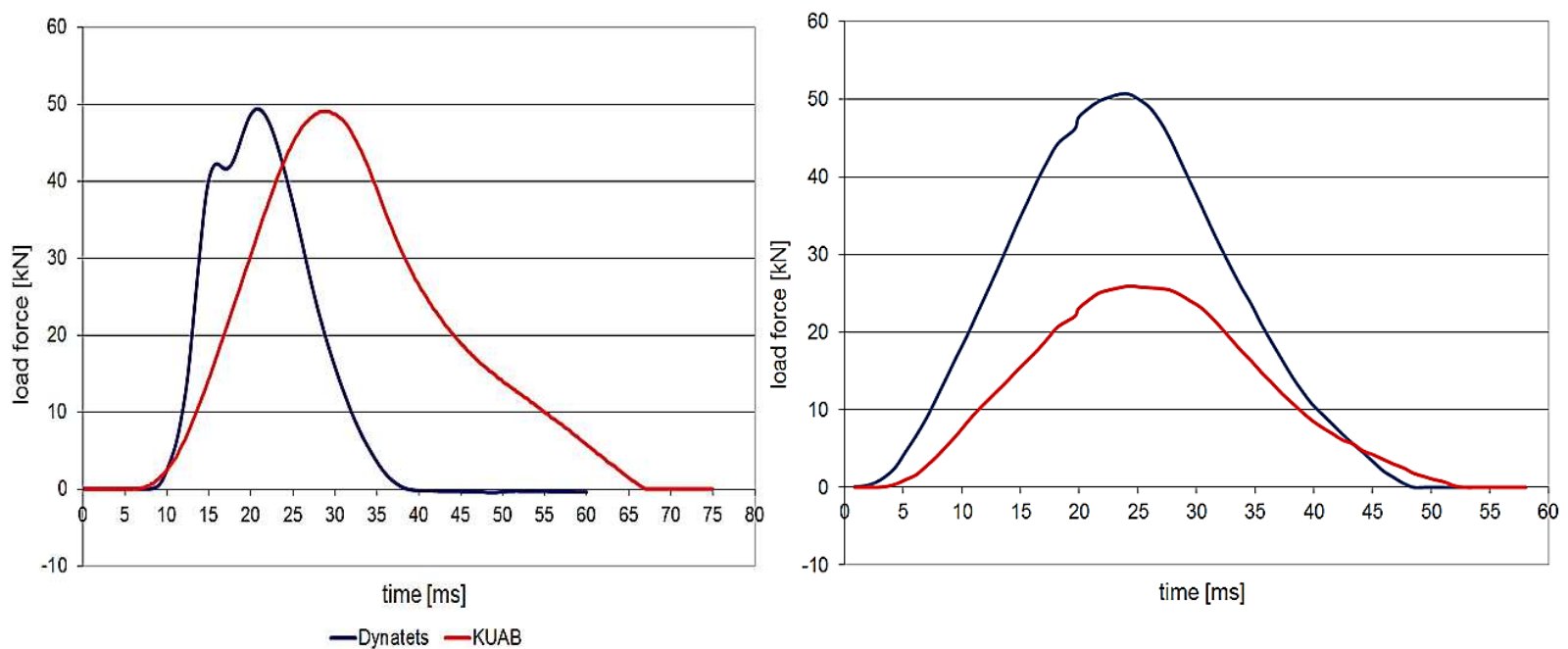

Fig. 1: The comparison of the load impulse shapes generated by FWD KUAB and FWD Dynatest (on the left) and two drop heights by FWD KUAB (on the right).

Each of pavements was tested at least at four points. Some variations as for the maximum load force values and the load impulse time were observed at the individual positions (Table 1 and Table 2).

Table 1: The FWD KUAB load force and impulse time variations.

\begin{tabular}{|c|c|c|c|c|c|}
\hline \multirow{2}{*}{ Pavement } & \multirow{2}{*}{ Value } & \multicolumn{2}{|c|}{ Drop height 1 } & \multicolumn{2}{c|}{ Drop height 2 } \\
\cline { 3 - 6 } & & max. load force & load impulse time & max. load force & load impulse time \\
\hline \multirow{3}{*}{$1-6$} & $\min$ & 25.10 & 49.39 & 49.50 & 45.06 \\
\cline { 2 - 6 } & $\max$ & 25.90 & 53.73 & 51.50 & 50.26 \\
\cline { 2 - 6 } & average & 25.53 & 51.49 & 50.39 & 48.17 \\
\hline
\end{tabular}

Table 2: The load force and impulse time variations of two used FWDs.

\begin{tabular}{|c|c|c|c|c|c|}
\hline \multirow{2}{*}{ Pavement } & \multirow{2}{*}{ Value } & \multicolumn{2}{|c|}{ FWD KUAB } & \multicolumn{2}{c|}{ FWD Dynatest } \\
\cline { 3 - 6 } & & max. load force & load impulse time & max. load force & load impulse time \\
\hline \multirow{3}{*}{7} & $\min$ & 48.50 & 59.85 & 48.49 & 29.85 \\
\cline { 2 - 6 } & $\max$ & 49.50 & 61.02 & 51.11 & 30.40 \\
\cline { 2 - 6 } & average & 49.08 & 60.20 & 49.89 & 30.15 \\
\hline
\end{tabular}

To assess the waves propagation, the wave arrival time to a receiver had to be determined. Based on the findings presented in [7], the time span with the same maximum deflection value was chosen and the exact time of the wave occurrence at the receiver was calculated as the middle of the time span. Afterwards, time shift between specified exact time at the receiver at the load centre and the others was calculated for each test. Consequently, the data was used to determine the average values (Table 3). 
Table 3: Inputs for the assessment of the wave propagation.

\begin{tabular}{|c|c|c|c|c|c|c|c|c|}
\hline \multirow{3}{*}{ Pavement } & \multirow{3}{*}{ FWD } & \multirow{3}{*}{$\begin{array}{l}\text { Load } \\
\text { force } \\
{[\mathrm{kN}]}\end{array}$} & \multicolumn{6}{|c|}{$\begin{array}{l}\text { Average time shift of wave arrival time between the receiver in the centre of load } \\
\text { and others receivers [ms] }\end{array}$} \\
\hline & & & \multicolumn{6}{|c|}{ The distance of the receiver from the centre of load [mm] } \\
\hline & & & 300 & 450 & 600 & 900 & 1200 & 1500 \\
\hline \multirow{2}{*}{1} & \multirow{13}{*}{ KUAB } & 25.5 & 0.215 & 0.432 & 0.645 & 1.950 & 3.250 & 4.115 \\
\hline & & 50.0 & 0.106 & 0.325 & 0.541 & 1.948 & 2.599 & 4.330 \\
\hline \multirow{2}{*}{2} & & 25.5 & -0.432 & 0.218 & -0.432 & 0.433 & 2.600 & 3.468 \\
\hline & & 50.0 & 0.217 & 0.544 & 0.544 & 2.060 & 2.709 & 4.334 \\
\hline \multirow{2}{*}{3} & & 25.5 & -0.435 & -0.002 & -0.218 & 1.948 & 2.815 & 5.198 \\
\hline & & 50.0 & 0.434 & 0.759 & 0.974 & 2.600 & 4.008 & 5.741 \\
\hline \multirow{2}{*}{4} & & 25.5 & 0.647 & 0.865 & 0.647 & 2.818 & 4.333 & 5.418 \\
\hline & & 50.0 & 0.325 & 0.543 & 1.193 & 2.709 & 3.901 & 5.525 \\
\hline \multirow{2}{*}{5} & & 25.5 & 0.435 & 0.218 & -0.215 & 1.518 & 2.603 & 3.035 \\
\hline & & 50.0 & 0.434 & 0.869 & 0.543 & 1.735 & 2.276 & 4.010 \\
\hline \multirow{2}{*}{6} & & 25.5 & -0.215 & 0.000 & -0.650 & 0.435 & 1.950 & 3.250 \\
\hline & & 50.0 & 0.216 & 0.540 & 0.324 & 2.059 & 2.709 & 4.116 \\
\hline \multirow{2}{*}{7} & & 49.0 & 0.482 & 0.833 & 1.145 & 2.385 & 3.746 & 5.393 \\
\hline & Dynatest & 50.0 & 0.629 & 1.051 & 1.578 & 3.033 & 4.886 & 6.921 \\
\hline
\end{tabular}

\section{Discussion}

A generated wave propagates from a source to surroundings with the velocity depending on material properties in the depth relating to the frequency (wavelength) of applied load. When the propagation of a wave is registered by receivers placed at various distances from the source the travel time of the wave to a receiver should increase with the distance of the receiver from the source. This assumption is not always met when data in Table 3 are assessed. The main discrepancies are the negative values (i.e. the calculated exact time of the wave occurrence at a more distant receiver is shorter compared to receiver at the centre of load), the same or lower values in consecutive receivers (i.e. time of the wave occurrence at a more distant receiver is the same or shorter comparing to the previous receiver(s)). However, the contradictions were noticed only in a part of data and relate to the values calculated from the FWD KUAB tests on some pavements for the sensors placed up to $600 \mathrm{~mm}$ from the load centre (neglecting two values for the load force of $25.5 \mathrm{kN}$ at the distance of the receiver of $900 \mathrm{~mm}$ ). The reasons for this can be various, e.g. the short distance (offset) of these receivers from the source for these pavement structures thickness and layers material, sensitivity and accuracy of receivers, etc. No discrepancies were observed at the sensors up to $600 \mathrm{~mm}$ in the case of the pavement 7, regardless of the type of FWD. When the values determined for the sensors at the distance of $900 \mathrm{~mm}$ and more are examined it is evident they are significantly higher comparing to those up to $600 \mathrm{~mm}$. It could be considered the distance of the receivers $900 \mathrm{~mm}$ and more gives a possibility to assess the propagation of waves generated by FWD. Therefore, the next evaluation was done using data for the receivers positioned at the distance of 1200 and $1500 \mathrm{~mm}$ from the centre of load (to exclude possible errors at the distance of $900 \mathrm{~mm}$ ).

The influence of load magnitude on surface waves propagation was evaluated based on data derived from the tests on the pavements $1-6$ performed by FWD KUAB using different drop heights. Due to, the maximum of load force differed significantly $(25.5 \mathrm{kN}$ and $50 \mathrm{kN})$. However, besides that, the difference of approx. $3.5 \mathrm{~ms}$ was noticed as for the load impulse time. The velocity of a surface wave, that can be regarded as the Rayleigh wave, $c_{R}$, is in relation with its wavelength $\lambda_{R}$ and the frequency of a load impulse $f_{R}$ according to the formula

$c_{R}=\lambda_{R} \cdot f_{R}$.

Frequencies of an impulse have to differ sufficiently to generate a scale of wavelengths enabling to reveal dissimilarity of material properties of a site along its depth. A little bit higher frequency in the case of the $50 \mathrm{kN}$ load force implies a lower depth range, and probably, a thinner part 
of pavement subgrade was affected. Nevertheless, the difference of the depth of waves propagation should not be high. Therefore, similar or approximately the same material properties can be expected to result in none or small differences of the wave velocity. It means, time to reach a receiver at the same distance should be also identical for both load force or a little bit shorter when the load force of $50 \mathrm{kN}$ is taken into account. When data in Table 3 valid for the receivers positioned at $1200 \mathrm{~mm}$ and $1500 \mathrm{~mm}$ from the load centre are assessed from this point of view, a conflict has to be stated. Mostly, the average time shifts representing travel time of a wave from source to a receiver are longer for the load force of $50 \mathrm{kN}$. A possible reason can be the magnitude of the $25.5 \mathrm{kN}$ load force impulse is lower than produced by load force of $50 \mathrm{kN}$ and the majority energy propagates closer to surface through materials having a higher bulk density than materials situated deeper. Due to, the velocity of waves is higher and inversely travel time is shorter. A confirmation of this assumption is in Fig. 2 showing the difference of waves travel time to the receivers at the distance of $1200 \mathrm{~mm}$ and $1500 \mathrm{~mm}$.

Data in Fig. 2 can be used to assess the influence of pavement structure composition on surface waves propagation. It is mentioned above the thickness of all pavements was the same, the asphalts used to build the wearing, base and upper sub-base layer differed on by type of binder. The most important fact relevant to the velocity of waves is related to the material of the bottom sub-base layer. The unbound material was used in the pavements 3 and 4 ; the cement bound materials were applied in the others. The subgrade modulus was $90 \mathrm{MPa}$ (pavements 3 and 4) or $60 \mathrm{MPa}$ (pavements 1,2, 5 and 6). Therefore, the time of waves propagation between the receivers at the distance of $1200 \mathrm{~mm}$ and $1500 \mathrm{~mm}$ in Fig. 2 should be longer for the pavements 3 and 4 . However, only the value for pavement 3 and the load force $25.5 \mathrm{kN}$ is in the accordance with this assumption. No significant difference is observed when data for the load force of $50 \mathrm{kN}$ are examined. The values in Fig. 2 are calculated using the short distance of the receivers $(300 \mathrm{~mm})$ than can misrepresent reality. Nevertheless, data in Table 3 prove higher time shifts for the pavements 3 and 4 , especially at the receiver position of $1500 \mathrm{~mm}$.

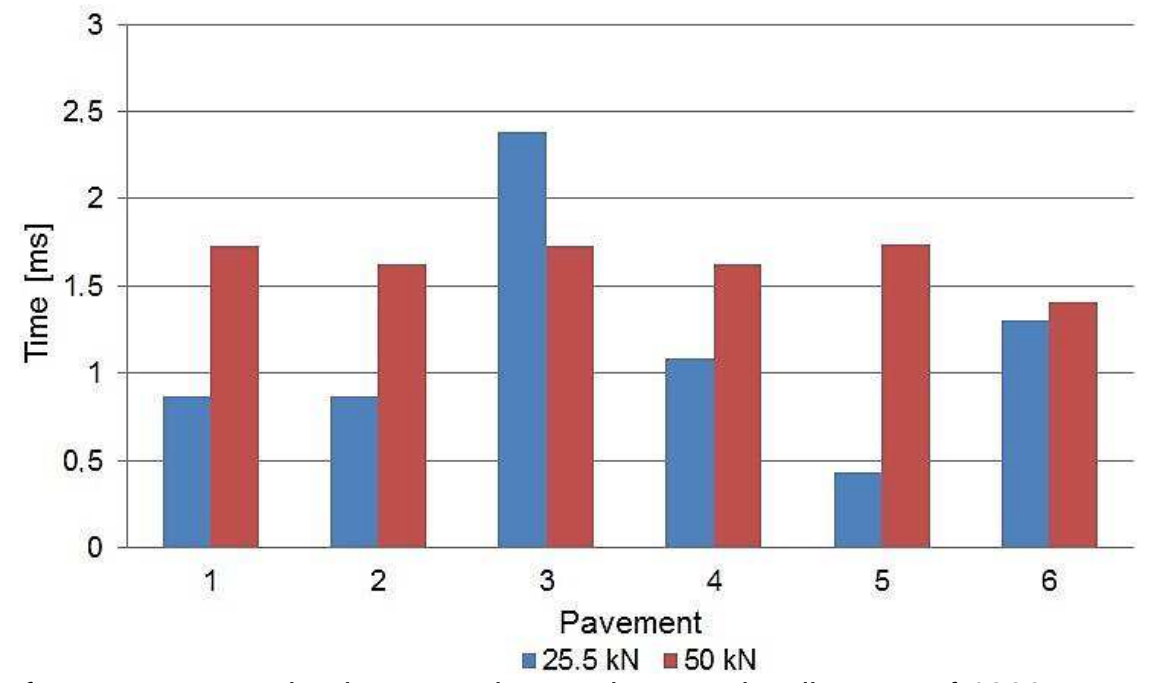

Fig. 2: Time of waves propagation between the receivers at the distance of $1200 \mathrm{~mm}$ and $1500 \mathrm{~mm}$.

It was mentioned the difference of the impulse time generated two load forces was low and theoretical assumptions of its impact on the waves propagation was not in accordance with obtained results in the case of the pavements $1-6$. However, the impulse time at the tests on the pavement 7 differed noticeably. As the load force was approximately the same, the different load time should be the only reason for potential distinctions. As it is evident in Fig. 3 the travel time is different and longer for the shorter (FWD Dynatest) load impulse. It was expected the shorter impulse generates the shorter wavelength that propagates closer to the top of pavement surface with the higher velocity and shorter time. The result is diametrically opposite, however in the accordance with the result for two load forces of FWD KUAB (i.e. shorter impulse time - longer travel time of wave to a receiver). An explanation related to the difference in load impulse magnitude was discussed above to explain the contradiction. As the load impulse magnitude of the FWD Dynatest is lower comparing to FWD KUAB (due to shorter load impulse time, although the load force was nearly same) similar explanation suggests itself. However, no analogy exists because shorter travel time for the FWD Dynatest should be recorded. 


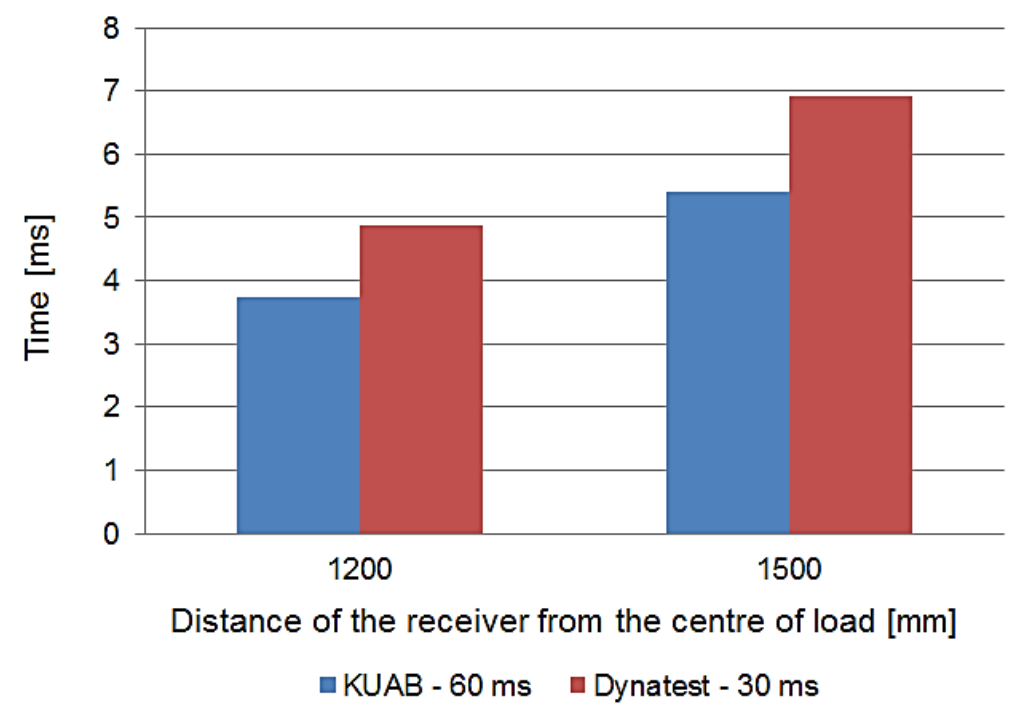

Fig. 3: Travel time of wave generated by two FWD.

\section{Conclusions}

The propagation of waves generated by load impulse of FWD KUAB and FWD Dynatest was assessed using diagnostics outputs in the form of time history data. Arrival time/wave occurrence to/at a receiver was determined as the middle of time span with the same maximum value of deflection. The calculated travel time of wave between the receiver in the centre of load and others receivers showed the contradiction with the theory as for the receivers up to $600(900) \mathrm{mm}$ from the source (centre of load). Therefore, data collected by the sensors positioned at the distance of 1200 and $1500 \mathrm{~mm}$ were used.

The influence of load magnitude on the waves propagation was investigated via the different load force with approximately the same load time and vice versa. Expectations relating to the travel time of waves, depending on the differences of load impulse, were not met. The shorter travel time of waves was detected in the case of the lower frequencies. The use of load impulse magnitude as a possible explanation was not successful because opposite tendencies in travel time were noticed.

The outputs of tests performed on six pavements with the same total thickness but the different material in the bottom sub-base layer (unbound or cement bound material) were used to assess the influence of pavement structure composition on surface waves propagation. Expected longer travel time of waves in the pavements with unbound materials was confirmed taking into account travel time between the centre of load and the receiver at the distance of $1200 \mathrm{~mm}$ (or $1500 \mathrm{~mm}$ ). When travel time between the mentioned two receivers was used the expectations were not always met.

\section{Acknowledgement}

This article was produced with the financial support of the Scientific Grant Agency of the Ministry of Education, Science, Research and Sport of the Slovak Republic and Slovak Academy of Science under grant VEGA 1/005/16 Modelling of selected dynamic problems in time and frequency domain and the financial support of the Ministry of Education, Youth and Sports within the National Sustainability Programme I, project of Transport R\&D Centre (LO1610), on the research infrastructure acquired from the Operation Programme Research and Development for Innovations (CZ.1.05/2.1.00/03.0064).

\section{References}

[1] EUROPEAN COMMISSION COST 336 Use of Falling Weight Deflectometer in Pavement Evaluation. Final Report, $2^{\text {nd }}$ edition. Luxembourg, Office for Official Publications of the European Communities, 2005, $392 \mathrm{p}$.

[2] SPIELHOFER, R. et al.: Guidelines of a complex methodology for nondestructive pavement measuring techniques. Final report of WP 2, Task 2. Project Sustainable Pavements for European New Member States, Sixth framework programme of European Commission, 2009. 
[3] SA'DON, N. M. - PENDER, M. J. - KARIM, A. R. A.: Dynamic Soil Stiffness between WAK, SASW and SCPT Tests, 2014. In: Hassan R., Yusoff M., Ismail Z., Amin N., Fadzil M. (eds) InCIEC 2013, Springer, Singapore, doi.org/10.1007/978-981-4585-02-6_40.

[4] NAZARIAN, S. - STOKOE, K. H. II.: In Situ Shear Wave Velocities from Spectral Analysis of Surface Waves. $8^{\text {th }}$ World Conference on Earthquake Engineering, San Francisco, California, Vol. III, 1984, pp. 31 - 38.

[5] RICHART Jr, F. E. - WOOD, R. D. - HALL Jr, J. R.: Vibration of Soils and Foundations. PrenticeHall, New Jersey, 1970.

[6] FOTI, S. - HOLLENDER, F. - GAROFALO, F. et al.: Guidelines for the good practice of surface wave analysis a product of the InterPACIFIC project. Bulletin of Earthquake Engineering, Vol. 16, Iss. 6, 2018, pp. 2367 - 2420, https://doi.org/10.1007/s10518-017-0206-7.

[7] KOMAČKA, J.: An accuracy problem of the FWD time history with regard to the application of the SASW method. Civil and Environmental Engineering, Vol. 13, Iss. 2, 2017, pp. 120 - 124, DOI: 10.1515/cee-2017-0016. 